\title{
Holoprosencephaly from the Otolaryngology Perspective-Case Report
}

\author{
Ibrahim Alarifi ${ }^{1}$, Abdullah Alabdulqader ${ }^{2}$, Ameen Binnasser ${ }^{3}$ and Tariq Tatwani ${ }^{4 *}$ \\ ${ }^{1}$ Department of Otorhinolaryngology, Security Forces Hospital, Saudi Arabia \\ ${ }^{2}$ Department of Otorhinolaryngology, Al Imam Mohammad Ibn Saud Islamic University, Saudi Arabia \\ ${ }^{3}$ Department of Otorhinolaryngology, King Fahad Medical City, Riyadh, Saudi Arabia \\ ${ }^{4}$ Department of Otorhinolaryngology, Prince Sultan Military Medical City, Saudi Arabia
}

*Corresponding author: Tariq Tatwani, Department of Otorhinolaryngology, Prince Sultan Military Medical City, Riyadh, Saudi Arabia.

Received Date: January 31, 2020

Published Date: February 18, 2020

\section{Introduction}

Craniofacial anomalies are common among patients with diagnosis of Holoprocencephaly. We are reporting a rare case of holoprocencephaly with single nostril, congenital nasal piriform aperture stenosis, and choanal atresia who was managed and still following with us.

\section{Case Report}

We present a 4-month-old girl who was born after uneventful pregnancy and was a product of spontaneous vaginal delivery, which was done outside our hospital, she was full term, and her birth weight $3.3 \mathrm{~kg}$ with low Apgar score and intubated shortly thereafter. She has been admitted to NICU post-delivery and tracheotomy was performed at 3 months of age without any further documentation. Both parents were Saudis, non-consanguineous, and healthy. The father age was 31-year-old and the mother 30 -year-old with no history of abortion. No family history of metabolic or inherited disease. The mother denied any exposure to alcohol, teratogenic agents, irradiation, or infectious diseases during her pregnancy. The chromosomal analysis done and resulted as: $46 \mathrm{XX}$ with terminal deletion on the short arm of chromosome 18p11.3. The otolaryngologist on call has been consulted to assess it her because of respiratory distress and episodes of cyanosis and de-saturation which has been relieved by Ambu-bagging with 100 \% oxygen (Figure 1).

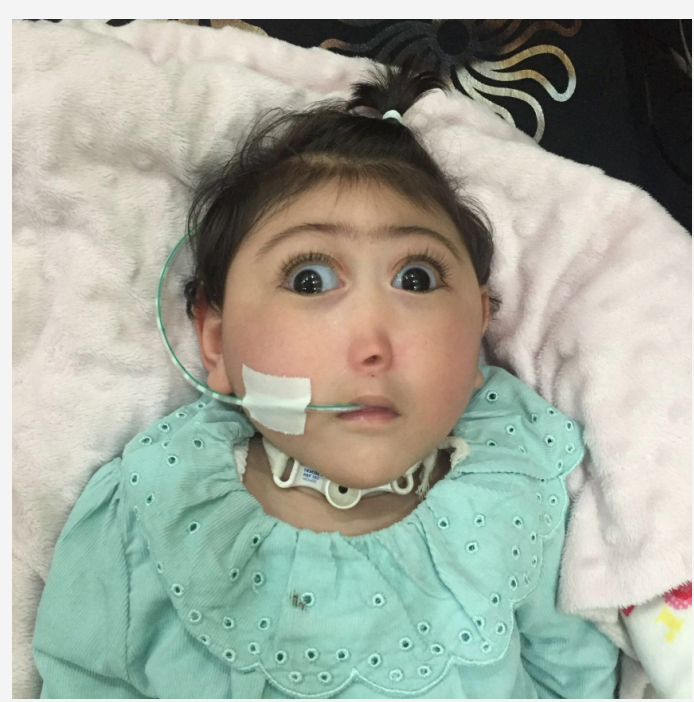

Figure 1:The dysmorphic features of the patient. An informed consent was taken from the mother to release this picture. 
The child was on tracheotomy tube with multiple facial dysmorphic features which includes: Cebocephaly with blind ended single nostril, ocular hypotelorism, microcephaly, and micrognathia (Figure 1). At that time, she was breathing on room air and her color was pink and not in respiratory distress. Flexible fibro-optic scope passed through the tracheotomy tube and showed hard yellowish mucous plug obstructing $50 \%$ of the lumen which was changed to a new tube without any complication. Flexible fibro-optic scope through the single nostril showed bilateral inferior turbinate touching each other without septum, scope could not be passed beyond anterior end of inferior turbinates. Patient came with a report of CT scan brain shows monoventricle, rudimentary occipital horn fused thalami. She has been diagnosed as Holoprosencephaly semi-lobar type. The parents refused MRI to be done. Echocardiography was done and showed small secundum ASD, with left to right shunting.

At age of 1 year, CT sinuses was performed and showed the following findings: multiple midline facial congenital abnormalities including central maxillary incisor, congenital nasal pyriform aperture stenosis (CNPAS), bilateral posterior choanal atresia, and hypoplastic sphenoid bone. Direct laryngobroncoscpe done and shows normal anatomy down to the tracheotomy tube except the presence of suprastomal collapse. Patient feed by orogastric tube as family refused permanent feeding tube. A follow up flexible fibroptic scope at age of 3 years showed details distal to the head of inferior turbinates including: no septum, vertical rudimentary middle turbinate bilaterally, and blind pouch nasal cavity posteriorly. Teeth start eruption with saw appearance. Hard and soft palate, tongue, bilateral ear examination all was normal. Now the baby is a 3-yearold and since she is still on trachestomy, surgical intervention was delayed for further rooming and growth of nasal cavity.

\section{Discussion}

Holoprosencephaly (HPE) is a structural anomaly of the brain resulting from failed or incomplete forebrain division occurring between the 18th and the 28th day of gestation [1,2]. HPE is an autosomal dominant disease and is mostly due to the sonic hedgehog gene mutations [3]. Whereas solitary median maxillary central incisor (SMMCI) syndrome (phenotype) is a congenital disease, probably a developmental field defect, arising from a nonclear genetic abnormality occurring between the $35^{\text {th }}$ and $38^{\text {th }}$ days in utero, and affecting midline structures of the head including the cranial skeleton, the maxilla and its contained teeth (the central incisor tooth germs), the nasal passage (choanal atresia, midnasal stenosis or congenital pyriform aperture stenosis), and sometimes the brain tissue (holoprosencephaly), together with other midline structures [4]. When HPE is present, clinical picture is hugely variable ranging from alobar HPE and cyclopia to mild of HPE [5-7].

\section{Types of Holoprosencephaly}

Alobar HPE, the most severe, in which there is a single ventricle and no separation between the cerebral hemispheres. Semi lobar
HPE, in which the left and right frontal and parietal lobes are fused and the interhemispheric fissure only posteriorly present [2] Lobar HPE, in which most of the right and left cerebral hemispheres and lateral ventricles are separated but the frontal lobes are fused, more in the ventral part. Middle interhemispheric fusion variant, which manifest as no separation between the posterior frontal and parietal lobes, with varying lack of cleavage of the basal ganglia and thalami and absence of the body of the corpus callosum but presence of the genu and splenium of the corpus callosum $[3,8]$.

\section{Clinical features}

It may be predicted qualitatively by the specific neuroanatomical abnormalities present. These features can include characteristic craniofacial anomalies, ophthalmological abnormalities such as colobomata or microphthalmia, severe mental retardation or short stature and failure to thrive, pituitary dysfunction including diabetes insipidus, or motor dysfunction, autonomic dysfunction, feeding difficulties and seizures (sometimes difficult to treat). Severely affected patients do not typically survive beyond early infancy; however, a common misperception is that children with HPE do not survive beyond early infancy, nonetheless a significant proportion of more mildly affected children (as well as some severely affected children) survive past age 12 months [5-10].

\section{Craniofacial anomalies}

Craniofacial anomalies accompany HPE in approximately $80 \%$ of patients with HPE and often lead to the diagnosis.6 Craniofacial findings tend to correlate with the type and severity of brain anomalies in addition to causative gene if any. Patients with alobar HPE may be found to have cyclopia (the most severe presentation), proboscis, severe microcephaly and bilateral cleft lip and palate. Features in less severely affected patients may include microcephaly, hypotelorism, a flat nasal bridge and cleft lip or palate. The least severe spectrum may include hypotelorism, solitary maxillary central incisor and microcephaly. Malformations of the nose include complete absence, agenesis of the nasal cartridge, and proboscis (flat nose with a single central nostril without nasal bones). Nonetheless patient with severe form might have subtle craniofacial anomalies [11-19].

\section{Etiology}

Several Etiology has been proposed to cause HPE like environmental causes i.e. maternal diabetes mellitus, hereditary is evident in part of patient with HPE which could be cytogenetic abnormalities (numeric chromosomal abnormalities or structural chromosomal abnormalities), molecular abnormalities or mutations in single genes [11,20-23].

\section{Diagnosis}

The diagnosis is typically initiated by prenatal neurological imaging, abnormal physical examination, and or positive family history. Whenever possible, complete physical examination looking for dysmorphic features is needed. For the diagnosis of the specific 
neurologic findings and holoprosencephaly in precise, brain imaging is needed, which is essential for proper counseling of the patient and the family and therefore affecting the prognosis. Ultrasound can be used for this purpose and can be performed as long as the fontanelles are patent, in addition to CT scan, which carries risks associated with radiation exposure. However, MRI provides the best quality and should be the option whenever available. If a patient is found to have microcephaly, a large dorsal cyst, or rapidly enlarging head size, serial imaging is indicated [24-26].

Congenital nasal Piriform aperture stenosis and choanal atresia among holoprocencephaly: All the three types of congenital nasal cavity malformations: (choanal atresia, mid-nasal stenosis, and nasal pyriform aperture stenosis) can be present in association with solitary median maxillary central incisor (SMMCI) [27]. A study of 20 cases of congenital nasal pyriform aperture stenosis (CNPAS) found (SMMCI) in $60 \%$ of the patients [28]. For (CNPAS) Abbeele et al. suggested that surgical enlargement must be considered when relief of nasal obstruction could not be successful with conservative treatment within 10-15 days [29]. In a case series, 12 out of 15 patients needed surgical intervention in their first year of life [30].

\section{Conclusion}

A holoprocencephaly can present with any form of congenital nasal anomaly. In our rare case the patient has a unique combination of single nostril, CNPAS, and choanal atresia. Luckily our patient was referred to our center already trached which gave us the time to delay the surgical correction. Interestingly with this form of severe malformations the baby still alive and she is in her $3^{\text {rd }}$ year of life.

\section{Acknowledgement}

None.

\section{Conflict of Interest}

The authors declare no conflict of interests.

\section{References}

1. Dubourg C, Bendavid C, Acquire L, Henry C, Odent S, et al. (2007) Holoprosencephaly. Orphanet J Rare Dis 2: 1-8.

2. Solomon BD, Gropman A, Muenke M (2000) Holoprosencephaly Overview. In: Pagon RA, Adam MP, Ardinger HH, (Eds.) GeneReviews $®$ [Internet]. Seattle (WA): University of Washington, Seattle, USA.

3. U Hehr, C Gross, U Diebold, D Wahl, U Beudt, et al. (2004) Wide phenotypic variability in families with holoprosencephaly and a sonic hedgehog mutation. Eur J Pediatr 163: 347-352.

4. Roger K Hall (2006) Solitary median maxillary central incisor (SMMCI) syndrome. Orphanet Journal of Rare Diseases.

5. Berry SA, Pierpont ME, Gorlin RJ (1984) Single central incisor in familial holoprosencephaly. J Pediatr 104: 877-880.

6. Fryns JP, Van den Berghe H (1988) Single central maxillary incisor and holoprosencephaly. Am J Med Genet 30: 943-944.

7. Barkovich AJ, Quint DJ (1993) Middle interhemispheric fusion: an unusual variant of holoprosencephaly. AJNR Am J Neuroradiol 14: 431440
8. Hahn JS, Barnes PD (2010) Neuroimaging advancesin holoprosencephaly: refining the spectrum of the midline malformation. Am J Med Genet Part C Semin Med Gene 154C: 120-132.

9. Hahn JS, Barkovich AJ, Stashinko EE, Kinsman SL, Delgado MR, et al. (2006) Factor analysis of neuroanatomical and clinical characteristics of holoprosencephaly. Brain Dev 28: 413-419.

10. Lazaro L, Dubourg C, Pasquier L, Le Duff F, Blayau M, et al. (2004) Phenotypic and molecular variability of the holoprosencephalic spectrum. Am J Med Genet A 129A: 21-24.

11. Dubourg C, Bendavid C, Pasquier L, Henry C, Odent S, et al. (2007) Holoprosencephaly. Orphanet J Rare Dis 2: 1-8.

12. Plawner LL, Delgado MR, Miller VS, Levey EB, Kinsman SL, et al (2002) Neuroanatomy of holoprosencephaly as predictor of function: beyond the face predicting the brain. Neurology 59: 1058-1066.

13. Solomon BD, Lacbawan F, Mercier S, Clegg NJ, Delgado MR, et al (2010) Mutations in ZIC2 in Human Holoprosencephaly: description of a novel ZIC2-specific phenotype and comprehensive analysis of 157 individuals. J Med Genet 47: 513-524.

14. Lacbawan F, Solomon BD, Roessler E, El Jaick K, Domené S, et al. (2009) Clinical spectrum of SIX3-associated mutations in holoprosencephaly: correlation between genotype, phenotype and function. J Med Genet 46: 389-398.

15. Cohen MM (2006) Holoprosencephaly: clinical, anatomic, and molecular dimensions. Birth Defects Res A Clin Mol Teratol 76: 658-673.

16. Barkovich AJ, Simon EM, Clegg NJ, Kinsman SL, Hahn JS (2002) Analysis of the cerebral cortex in holoprosencephaly with attention to the sylvian fissures. AJNR Am J Neuroradiol 23: 143-150.

17. Barkovich AJ, Quint DJ (1993) Middle interhemispheric fusion: an unusual variant of holoprosencephaly. AJNR Am J Neuroradiol 14: 431440.

18. Hahn JS, Barkovich AJ, Stashinko EE, Kinsman SL, Delgado MR (2006) Factor analysis of neuroanatomical and clinical characteristics of holoprosencephaly. Brain Dev 28: 413-419.

19. Hennekam RC, Van Noort G, de la Fuente FA, Norbruis OF (1991) Agenesis of the nasal septal cartilage: another sign in autosomal dominant holoprosencephaly. Am J Med Genet 39: 121-122.

20. Barr M, Hanson JW, Currey K, Sharp S, Toriello H, et al. (1983) Holoprosencephaly in infants of diabetic mothers. J Pediatr 102: 565568

21. Muenke M, Beachy PA (2001) Holoprosencephaly. In: Scriver CR, Beaudet AL, Sly WS, Valle D, Childs B, Vogelstein B, eds. The Metabolic and Molecular Bases of Inherited Disease ( $8^{\text {th }}$ edn.), New York, NY: McGraw Hill 6203-6230.

22. Solomon BD, Rosenbaum KN, Meck JM, Muenke M (2010) Holoprosencephaly due to numeric chromosome abnormalities. Am J Med Genet C Semin Med Genet 154C: 146-148.

23. Bendavid C, Rochard L, Dubourg C, Seguin J, Gicquel I, et al. (2009) ArrayCGH analysis indicates a high prevalence of genomic rearrangements in holoprosencephaly: an updated map of candidate loci. Hum Mutat 30: 1175-1182.

24. Hahn JS, Barnes PD (2010) Neuroimaging advancesin holoprosencephaly: refining the spectrum of the midline malformation. Am J Med Genet C Semin Med Genet 154C: 120-132.

25. Hahn JS, Plawner LL (2004) Evaluation and management of children with holoprosencephaly. Pediatr Neurol 31: 79-88.

26. Raam MS, Solomon BD, Muenke M (2011) Holoprosencephaly: a guide to diagnosis and clinical management. Indian Pediatrics 48(6): 457-466.

27. Solitary median maxillary central incisor, short stature, choanal atresia/ midnasal stenosis. 
28. Larry J, Peterson Van Den Abbeele T, Triglia JM, Francois M, Narcy P (2001) (SMMCI) syndrome, Oral and Maxillofacial Surgery, Congenital nasal pyriform aperture stenosis: diagnosis and management of 20 cases. Ann Otol Rhinol Laryngol 110: 70-75.

29. T Van Den Abbeele, JM Triglia, M Francois, P Narcy (2001) Congenital nasal pyriform aperture stenosis: diagnosis and management of 20 cases. Ann Otol Rhinol Laryngol 110: 70-75.
30. A Losken, FD Burstein, JK Williams (2002) Congenital nasal pyriform aperture stenosis: diagnosis and treatment. Plast Reconstr Surg 109: 1506-1511. 